\title{
SYT7 acts as an oncogene and a potential therapeutic target and was regulated by $\triangle N p 63 a$ in HNSCC
}

You Fu ${ }^{1,3+}$, Guocai Tian ${ }^{1,3+}$, Zhiyuan Zhang ${ }^{1,3^{*}}$ and Xiao Yang ${ }^{2,3^{*}}$ (1)

\begin{abstract}
Background: Head and neck squamous cell carcinoma (HNSCC) are one of the most common types of head and neck cancer, and it is urgent to find effective treatment for advanced patients. Exploring developing and progressing mechanisms of HNSCC could provide a theoretical basis to find new therapeutic targets.
\end{abstract}

Methods: In our research, we performed a whole-gene expression profile microarray analysis to identify differential expression genes between squamous cell carcinoma cells and $\triangle N p 63$ alpha ( $\triangle N p 63 a$ ) knockdown cells. As a result, an important gene Synaptotagmin VII (SYT7) was screened out.

Results: SYT7 knockdown affected the proliferation, apoptosis and cell cycle of squamous cell carcinoma cells. The rescue experiment in vitro with $\triangle N p 63 a$ and SYT7 double knockdown resulted in partial reversion of $\triangle N p 63 a-$ induced phenotypes. This was also confirmed by experiments in vivo.

Conclusions: Taken together, we found that $\triangle N p 63$ a could inhibit the occurrence and progression of HNSCC throughout downregulating the expression of SYT7. Therefore, SYT7/ NNp63a axis could be a potential therapeutic target for clinical treatment of HNSCC.

Keywords: $\triangle \mathrm{Np} 63$ alpha, SYT7, Head and neck squamous cell carcinoma, TCGA, microarray

*Correspondence: Zhiyuan.Zhang@sh9hospital.org.cn; 113023@sh9hospital. org.cn

${ }^{\dagger}$ You Fu and Guocai Tian contributed equally to this work

1 Department of Oral and Maxillofacial-Head Neck Oncology, Shanghai Ninth People's Hospital, Shanghai Jiao Tong University School

of Medicine, College of Stomatology, National Center for Stomatology, National Clinical Research Center for Oral Diseases, Shanghai Jiao Tong University, 639 Zhizaoju Road, Shanghai 200011, People's Republic of China

${ }^{2}$ Department of Oral and Cranio-maxillofacial Surgery, Shanghai Ninth People's Hospital, Shanghai Jiao Tong University School of Medicine, College of Stomatology, National Center for Stomatology, National Clinical Research Center for Oral Diseases, Shanghai Jiao Tong University, 639 Zhizaoju Road, Shanghai 200011, People's Republic of China Full list of author information is available at the end of the article

\section{Introduction}

Head and Neck Cancer (HNC) is one of the ten most common malignant tumors worldwide. Advanced HNC patients may have various physiological dysfunctions and eating, speaking, breathing, audio-visual disorders, thus, seriously impacting health and life quality of patients. Head and neck squamous Cell Carcinoma (HNSCC) is the most common type of HNC, accounting for more than $90 \%$ of HNC. It is the sixth most common malignant tumor disease in the world $[1,2]$. There are around 60,000 new cases every year, twothirds of which are advanced patients at the III, IV stages $[3,4]$. There are two thirds of HNSCC patients in developing countries. In China, HNSCC accounted for about $10 \%$ of the whole-body malignant tumors, and the trend of its incidence and fatality rate increased original author(s) and the source, provide a link to the Creative Commons licence, and indicate if changes were made. The images or other third party material in this article are included in the article's Creative Commons licence, unless indicated otherwise in a credit line to the material. If material is not included in the article's Creative Commons licence and your intended use is not permitted by statutory regulation or exceeds the permitted use, you will need to obtain permission directly from the copyright holder. To view a copy of this licence, visit http://creativecommons.org/licenses/by/4.0/. The Creative Commons Public Domain Dedication waiver (http://creativeco mmons.org/publicdomain/zero/1.0/) applies to the data made available in this article, unless otherwise stated in a credit line to the data. 
year by year. HNSCC generally originates from the head and neck mucosal epithelium, with strong metastasis and high recurrence rate. Therefore, HNSCC is very prone to postoperative recurrence and cervical lymph node metastasis. Given the poor prognosis of HNSCC and the lack of effective diagnosis and treatment [5], the 5 -year survival rate of patients is only $50-60 \%$ [3, 6]. Therefore, it is particularly significant to explore the pathogenesis of HNSCC and to screen for specific diagnostic and prognostic biomarkers [7].

P53 transcription factor family, including p53 (TP53), p63 (TP63) and p73 (TP73), is a key player in tumor development and formation. p63 is expressed by two different promoters, resulting in two isoforms (TAp63 and DNp63) with or without amino $(\mathrm{N})$ terminal transactivation domain that is necessary to induce apoptosis and tumor inhibition $[8,9]$. Alternative splicing of the $3^{\prime}$ end of $\Delta$ Np63 mRNA produces $\alpha, \beta$ and $\gamma$ subtype [10]. Among them, $\Delta \mathrm{Np} 63 \alpha$ is the most abundant subtype detected in the basal layer of mucosa, skin and other epithelial tissues, and is a transcription factor regulating the expression of genes involved in cell adhesion [11]. There are reports that $\Delta \mathrm{Np} 63 \alpha$ overexpression is associated with malignant diseases including squamous cell carcinoma, such as head and neck cancer and skin cancer [12]. However, the role of $\Delta \mathrm{Np} 63 \alpha$ in different tumor progression seems to be inconsistent. The study by Jiarong Chen et al. confirmed that $\Delta \mathrm{Np} 63 \alpha$ promotes the progression of lung squamous cell carcinoma by overexpressing LINC00173.v1 [13]. Ectopic expression of $\Delta \mathrm{Np} 63 \alpha$ in patients with intrauterine adhesions induces EMT and endometrial fibrosis [14]. Ying Zhou et al. pointed out that in cervical squamous cell carcinoma, $\Delta \mathrm{Np} 63 \alpha$ can exert anti-tumor ability by inhibiting cell migration, invasion and tumor growth [15]. Hitherto, the role and molecular mechanism of $\Delta \mathrm{Np} 63 \alpha$ in the progress of HNSCC are not clear enough, we need to further explore.

Synaptotagmins were identified as the most common $\mathrm{Ca}^{2+}$ sensors of cell exocytosis. Synaptotagmin VII (SYT7) was one of the members of the synaptotagmin family and was indispensable for facilitation at several central synapses [16]. SYT7 was presynaptic and could affinitively bind to $\mathrm{Ca}^{2+}$ and increase residual $\mathrm{Ca}^{2+}$ which regulated facilitation [17]. Previous studies showed that SYT7 played a significant role in the proliferation, migration, apoptosis, and cell cycle in multiple solid tumors, such as colorectal cancer, gastric cancer, non-small cell lung cancer, renal cell carcinoma, glioblastoma, and melanoma [16, 18-22]. However, the role of SYT7 in HNSCC stayed unclear. Revealing the functions and mechanisms of SYT7 in the progression and development of HNSCC could be of great value for the diagnosis, prognosis, and therapy for HNSCC patients.
In our study, we established $\Delta \mathrm{Np} 63 \alpha$ overexpressed cells in two HNSCC cell lines. Affymetrix expression profile assay was performed and a new important oncogene SYT7 was screened out. Rescue experiment showed that $\Delta \mathrm{Np} 63 \alpha$ and SYT7 double knockdown could partially reverse the SYT7-induced phenotype. In general, $\Delta \mathrm{Np} 63 \alpha$ could inhibit the occurrence and progression of HNSCC throughout downregulating the expression of SYT7. $\triangle \mathrm{Np} 63 \alpha$ and SYT7 could be potential targets and have promising therapeutic strategy for HNSCC patients.

\section{Materials and methods \\ Cell culture}

The human HNSCC cell lines, Cal-27 and HN6, were purchased from the Chinese Academy of Sciences Cell Bank/Stem Cell Bank. All cells were cultured in DMEM medium with high glucose (ThermoFisher, 11965126, USA) supplemented with 10\% FBS (Gibco, 10100, USA) at $37{ }^{\circ} \mathrm{C}$ in a humidified atmosphere containing $5 \% \mathrm{CO}_{2}$.

\section{Lentivirus-mediated $\triangle N P 63 a$ overexpression, SYT7 knockdown and $\triangle$ NP63a, SYT7 double knockdown}

The lentivirus-mediated short hairpin RNA (shRNA) vector system was designed, constructed, packed and purified by Shanghai GeneChem Co, Ltd. (Shanghai, China), and all procedures were performed according to the manufacturer's protocol. Cal-27 and HN6 cells transfected with lentivirus, and $\triangle \mathrm{NP} 63 \alpha$ overexpression, shSYT7 and shSYT7 $+\operatorname{sh} \triangle \mathrm{NP} 63 \alpha$ cells were established respectively and used for subsequent experiments. Cal27 and HN6 cells transfected with blank lentivirus or lentivirus containing blank shRNA were used as a negative control, denoted as control group or shCtrl group. The multiplicity of infection was $10\left(2 \times 10^{5}\right.$ cells transfected per well and $2 \times 10^{6} \mathrm{TU}$ lentivirus transfected per well in a 6-well plate), and the infection was proceeded with the addition of DMEM and $5 \mu \mathrm{g} / \mathrm{mL}$ Polybrene (Clontech Laboratories, Inc., Mountainview, CA, USA) to the cells. The fluorescent microscopy (Olympus IX71; Olympus Corporation, Tokyo, Japan) demonstrated that the transfection efficiency of Cal-27 and HN6 cells transfected with gene-overexpressed, gene-shRNA and shCtrl lentivirus was $>80 \%$. The overexpression or knockdown efficiency of the target gene was detected by RT-qPCR and western blotting 3 days after transfection.

\section{RNA sequencing and data analysis}

Total RNA from HN6 cells transfected with $\operatorname{sh} \triangle \mathrm{NP} 63 \alpha$ and shCtrl lentivirus was extracted using Trizol Reagent (Life technologies, Carlsbad, CA, US) according to the standard operating procedure provided by the manufacturer, and was further purified by QIAGEN RNeasy Kit. The total RNA was amplified, labeled and purified by 
using GeneChip ${ }^{\circledR} 3^{\prime}$ IVT PLUS Reagent Kit (Affymetrix, Santa Clara, CA, US) followed standard operating procedure to obtain the biotin labeled cRNA. According to the hybridization standard process provided by Affymetrix expression profile chip, array hybridization was conducted by GeneChip ${ }^{\circledR}$ Hybridization, Wash and Stand Kit (Affymetrix). The chip results were scanned with GeneChip ${ }^{\circledR}$ Scanner 3000 (Affymetrix), and the original data was read by Command Console Software 4.0 (Affymetrix). The qualified data were normalized by Affy package in R software. Limma package in $\mathrm{R}$ software was used for differential gene screening, and the selection conditions were as follows: Fold Change $\leq 0.5$ or Fold Change $\geq 2$, and $P<0.05$. Then, the clusterProfiler package in $\mathrm{R} /$ Bioconductor was used to perform Gene Ontology (GO) analysis and Kyoto Encyclopedia of Genes and Genomes (KEGG) enrichment analysis based on the differentially expressed genes for further function and pathway enrichment analysis. Ingenuity Pathway Analysis (IPA) was used to analyze the interaction network between target gene and significantly enriched pathways and pathwayrelated differentially expressed molecules.

\section{Real-time polymerase chain reaction (PCR) analysis}

Total RNA was extracted using TRIzol reagent (Invitrogen, USA), and cDNA was synthesized using SuperScript IV (Invitrogen, USA) following the manufacturer's instructions. The expression of target gene mRNA was measured by qRT-PCR (StepOnePlus ${ }^{\mathrm{TM}}$ Real-Time PCR System, Thermo Fisher, 4376600) using SYBR Green technology. Thermocycling conditions were as follows: $95{ }^{\circ} \mathrm{C}$ for $60 \mathrm{~s}$, then 45 cycles of $95{ }^{\circ} \mathrm{C}$ for $10 \mathrm{~s}, 60^{\circ} \mathrm{C}$ for $30 \mathrm{~s})$. The forward and reverse primer sequences were provided in Additional file 1: Table S1. The average cycle threshold (CT) value of the target gene in each group was calculated, and the CT value of the internal reference gene was subtracted to determine the $\Delta C T$ value. The average $\Delta \mathrm{CT}$ value of the control group was calculated, and the $\Delta C T$ value of each group sample was subtracted to determine the $-\Delta \Delta C \mathrm{~T}$ value. The expression of gene mRNA was calculated by using the $2^{-\Delta \Delta C T}$ method. GAPDH was the internal reference gene. The values for the control group were set as 1 , and the values for the other groups were calculated as the fold changes relative to the control values.

\section{Western blot analysis}

Western blotting was used to detect the protein level in Cal-27 and HN6 cells. Proteins were extracted from cells using a lysis buffer (2\% 2-mercaptoethanol, 4\% SDS and $20 \%$ glycerol, $100 \mathrm{mM}$ Tris- $\mathrm{HCl}$ ), and the protein concentration was measured using a bicinchoninic acid (BCA) Protein Assay kit (Beyotime Institute of Biotechnology,
Haimen, China). A total of $20 \mu \mathrm{g}$ protein was separated by SDS-PAGE ( $10 \%$ gels), and transferred onto polyvinylidene fluoride membranes (EMD Millipore, Billerica, MA, USA). The membranes were blocked in Tris-buffered saline with Tween (TBST) containing 5\% non-fat milk overnight at $4{ }^{\circ} \mathrm{C}$. The membranes were then incubated with primary antibodies overnight at $4{ }^{\circ} \mathrm{C}$. The membranes were then washed three times in TBST. The membranes were incubated with a horseradish peroxidase-conjugated goat anti-mouse immuno-globulin secondary antibody for $2 \mathrm{~h}$ at room temperature, then washed three times in TBST. Bands were visualized using enhanced chemiluminescence (ECL; Pierce; Thermo Fisher Scientific, Inc.), according to the manufacturer's protocol. The antibodies were provided in Additional file 2: Table S2.

\section{Celigo analysis}

Cells were seeded at a density of $2.5 \times 10^{3}$ cells $/$ well in a 96-well plate at $72 \mathrm{~h}$ post-transfection (at $37{ }^{\circ} \mathrm{C}$ in an atmosphere of $5 \% \mathrm{CO}_{2}$ ). After plating, Celigo ${ }^{\circledR}$ Image Cytometer (Nexcelom, Lawrence, MA, USA) was used to evaluate the number of cells by scanning green fluorescence daily for 5 days at room temperature.

\section{MTT assay}

Cells transfected with lentivirus were seeded in the 96-well culture plates at 2000 cells per well. The medium was replaced once a day and a 96-well plate was selected for MTT determination for 5 consecutive days. $20 \mu \mathrm{L}$ MTT solution (Genview) was added into each well and incubated for $4 \mathrm{~h}$. $100 \mu \mathrm{L}$ DMSO solution was added into each well and shaken on a shaker for 2-5 min. Absorbance at $490 \mathrm{~nm}$ was recorded using the SpectraMax M5 microplate reader (Molecular Devices, Silicon Valley, CA, USA).

\section{Wound-healing assay}

$5 \times 10^{4}$ Cal-27 and HN6 cells transfected with lentivirus were inoculated into 96-well plates and cultured at $37{ }^{\circ} \mathrm{C}$ in an incubator with $5 \% \mathrm{CO}_{2}$, with 3 replicate wells per group. On the next day, 96 Wounding Replicator (VP408FH, VP scientific) was aimed at the center of the lower end of the 96-well plate, gently pushed up to form a scratch, and the plates were washed 2-3 times with serum-free medium. $0.5 \% \mathrm{FBS}$-containing medium was added to the 96-well plate, and the plate was scanned with Cellomics (ArrayScan VT1, Thermo) to obtain $0 \mathrm{~h}$ pictures. After $8 \mathrm{~h}$, the plate was scanned with Cellomics again to get the picture. The cell area was calculated and the cell migration ability was evaluated. 


\section{Flow cytometry analysis for apoptosis}

Fluorescence-activated cell sorting (FACS) was used to analyze the lentiviral efficiency at cell apoptosis. Cells transfected with lentivirus were plated in 6-cm dishes 5 days after transfection and grown to $85 \%$ confluence. Following washing with binding buffer [from the Annexin V-allophycocyanin (APC) Detection kit (cat. no. 88-8007; eBioscience; Thermo Fisher Scientific, Inc.)] once, cells were stained with $200 \mu \mathrm{L}$ binding buffer containing $10 \mu \mathrm{L}$ APC Detection kit for 10-15 min at room temperature in the dark. A flow cytometer (Merck KGaA) and InCyte 3.1 (Merck KGaA) were then used to analyze the cells.

\section{Flow cytometry analysis for cell cycle}

Fluorescence-activated cell sorting (FACS) was performed to analyze the cell cycle distribution of CAL-27 and HN6 cells after transfection with lentivirus. Cells transfected with lentivirus were seeded in $6-\mathrm{cm}$ dishes and grown to a coverage rate of approximately $80 \%$. After washing once with PBS pre-cooled at $4{ }^{\circ} \mathrm{C}$, the cells were fixed with $70 \%$ ethanol at $4{ }^{\circ} \mathrm{C}$ for $1 \mathrm{~h}$, and then washed once with PBS. The cell staining solution was prepared in the ratio of 25:10:1000 $(40 \times$ PI $(2 \mathrm{mg} / \mathrm{mL}, \mathrm{P} 4170$, Sigma $)$ : $100 \times$ RNase $(10 \mathrm{mg} / \mathrm{mL}, 2158-1$, TakaRa): $1 \times$ PBS $)$. The cells were resuspended with a certain volume of cell staining solution, and then analyzed using a flow cytometer (Merck KGaA).

\section{Immunohistochemical staining}

Tumor samples of patients with HNSCC were obtained between 2006 and 2018 from Shanghai Ninth People's Hospital. All patients signed the informed consent form. All the tumor samples were fixed with $4 \%$ paraformaldehyde (Sangon Biotech) and embedded in paraffin. 4- $\mu \mathrm{m}$-thick slides were performed and used for subsequent staining. Slides were incubated in $3 \% \mathrm{H}_{2} \mathrm{O}_{2}$ for $5 \mathrm{~min}$ to block endogenous peroxidase was with, and then blocked with $5 \%$ serum for $15 \mathrm{~min}$. Slides were incubated with primary antibodies (Abs) at $37^{\circ} \mathrm{C}$ for $2 \mathrm{~h}$, and with secondary antibody at $37^{\circ} \mathrm{C}$ for $45 \mathrm{~min}$. The samples were counterstained with hematoxylin (Absin Bioscience, Inc, abs9139) for 10-15 s. Finally, after dehydration, the slides were mounted with neutral gum. All IHC images were examined with a microscope (ZEISS Axioscope 5).

\section{Animal experiments}

Female BALB/c nude mice aged 4 weeks were purchased from the Charles River Laboratories. All mice were maintained under specific pathogen-free conditions in the animal facilities of the Ninth People's Hospital, and were divided into two groups at random. Cal-27 cells transfected with shSYT7 or shCtrl lentivirus were implanted by subcutaneous injection of $2 \times 10^{6}$ cells underneath the skin of right back. Tumor sizes were calculated as length $\times$ width $\times$ width $\times 0.5$. Before the mice were sacrificed, the mice were anesthetized with pentobarbital (Sigma-Aldrich, USA) at a dose of $80 \mathrm{mg} / \mathrm{kg}$ (injected intraperitoneally), and then the fluorescence intensity in the nude mice was observed and photographed using a small animal in vivo imaging system (LB983, Berthold technologies). Mice with volumes greater than $2000 \mathrm{~mm}^{2}$ were euthanized with $60 \%$ compressed $\mathrm{CO}_{2}$ gas at a flow rate of $20 \%$ chamber $\mathrm{vol} / \mathrm{min}$. All animal experiments were approved by and performed in accordance with the guidelines of the Shanghai Jiao Tong University School of Medicine.

\section{Statistical analysis}

The data were shown as the mean \pm SD. One-way or twoway analysis of variance (ANOVA) followed by Tukey's post hoc analysis was performed to identify any significant differences. A computer-based statistical package (SPSS, version 22.0) was utilized for the analysis and Graphpad prism version 8.0 was used for the production of statistical graphs. $P<0.05$ was regarded to indicate a statistically significant difference.

\section{Results}

Overexpression of $\Delta \mathrm{Np} 63 \mathrm{a}$ affects proliferation, apoptosis and cell cycle of HNSCC cell lines

We selected human HNSCC cell lines HN6 and CAL-27 and established $\triangle \mathrm{Np} 63 \alpha$-overexpressed cells (Additional

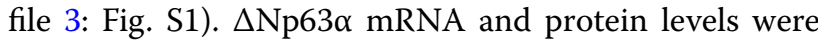
memorably upregulated in HN6 and CAL-27 cells transfected with $\triangle \mathrm{Np} 63 \alpha$-overexpressed lentivirus (Additional file 3: Fig. S1I-L). Celigo assays demonstrated that overexpression of $\Delta \mathrm{Np} 63 \alpha$ could significantly suppress the proliferation of HNSCC cells in vitro (Fig. 1A, B). Analogously, MTT assays also verified this result (Additional file 4: Fig. S2A, B). Wound-healing assays showed that overexpression of $\Delta \mathrm{Np} 63 \alpha$ also inhibited the migration of HNSCC cells (Fig. 1C, D). Then, flow cytometry was performed to the influence of overexpression of $\Delta \mathrm{Np} 63 \alpha$ on cell cycle and apoptosis. Results showed that overexpression of $\Delta \mathrm{Np} 63 \alpha$ could lead to increasing apoptosis of HNSCC cells (Fig. 2A, B) and significantly reduce the proportion of tumor cells in G1 phase (Fig. 2C, D).

\section{SYT7 was screened as a target gene of $\Delta \mathrm{Np} 63 \mathrm{a}$ and an oncogene in HNSCC}

To further clarify the downstream target genes of $\Delta \mathrm{Np} 63 \alpha$, we performed Transcriptional sequencing on $\Delta$ Np63 $\alpha$-knockdown cells and shCtrl cells. We identified several related genes through IPA analysis (Fig. 3A). Genes differentially expressed in $\Delta \mathrm{Np} 63 \alpha$-knockdown 


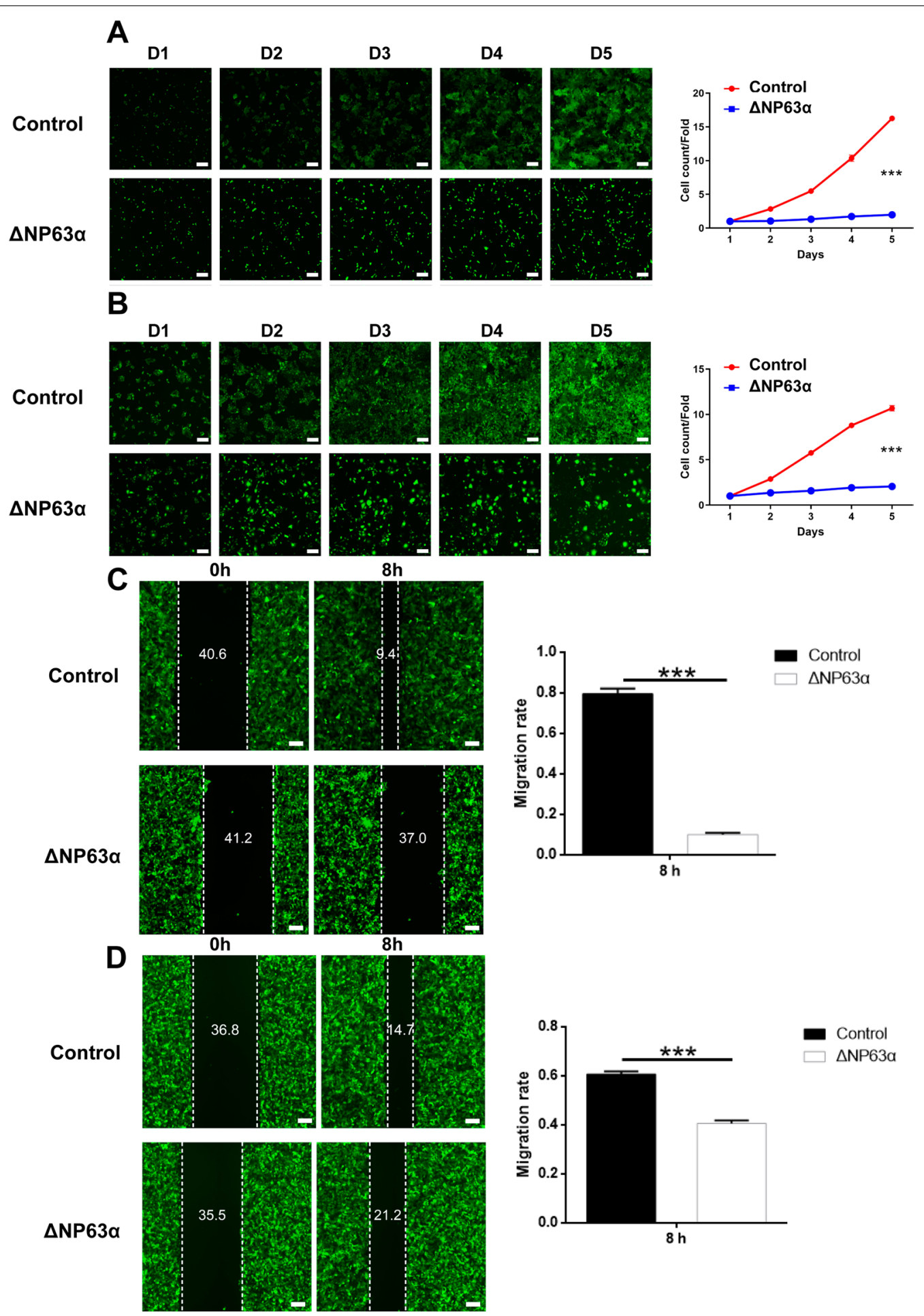

Fig. 1 Overexpression of $\triangle N$ P63a inhibited growth and migration of HN6 and CAL-27 cells. A Detection of cell proliferation of HN6 cells by Celigo cell count. B Detection of cell proliferation of CAL-27 cells by Celigo cell count. C Wound-healing assay of HN6 cells. D Wound-healing assay of CAL-27 cells $(n=3)$. Bars show the mean \pm SD. ${ }^{* * *}$ Represents $p<0.001$. Scale bar $=100 \mu \mathrm{m}$ 

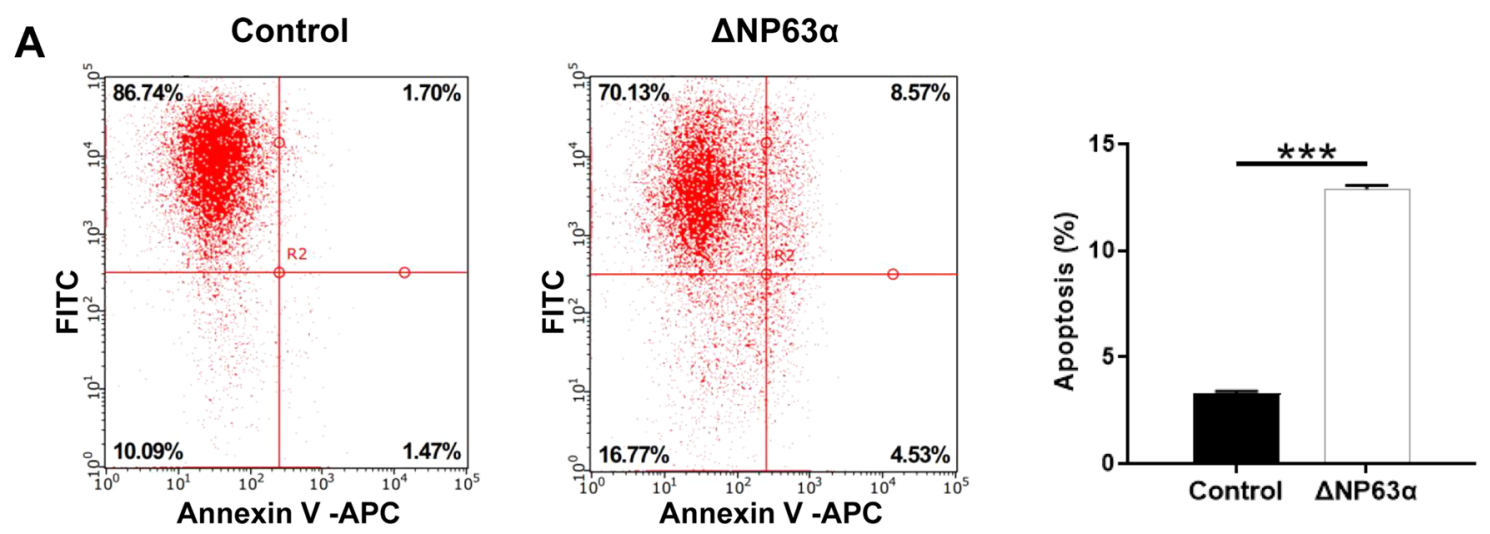

B
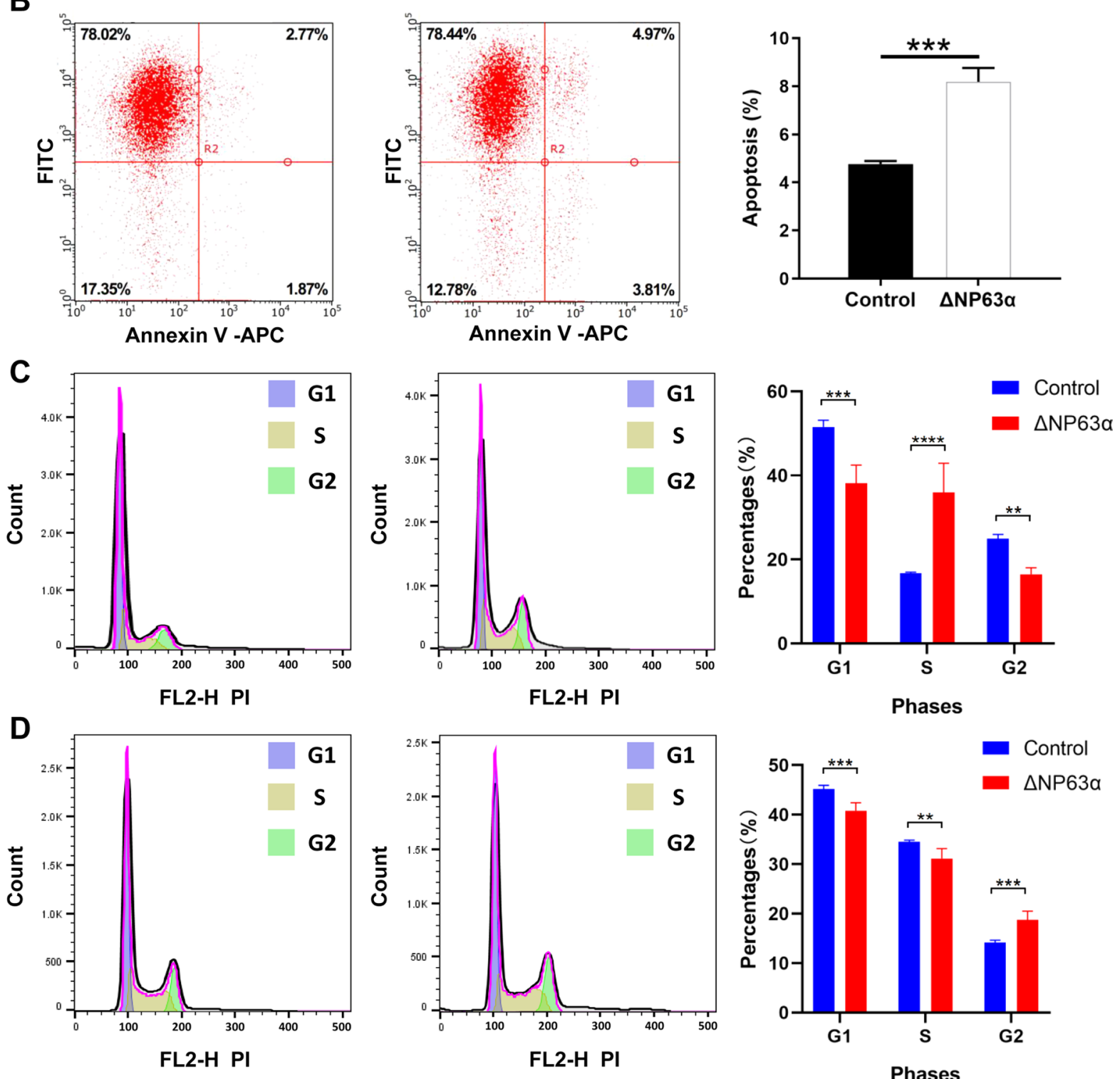

Fig. 2 Overexpression of $\triangle N P 63 a$ induced cell apoptosis and reduced the proportion of tumor cells in G1 phase in HN6 and CAL-27 cells. A Apoptosis assay of HN6 cells. B Apoptosis assay of CAL-27 cells. C Cell cycle detection of HN6 cells. D Cell cycle detection of CAL-27 cells ( $n=3$ ). Bars show the mean \pm SD. ${ }^{* *}$ Represents $p<0.01,{ }^{* * *}$ represents $p<0.001$ 
A

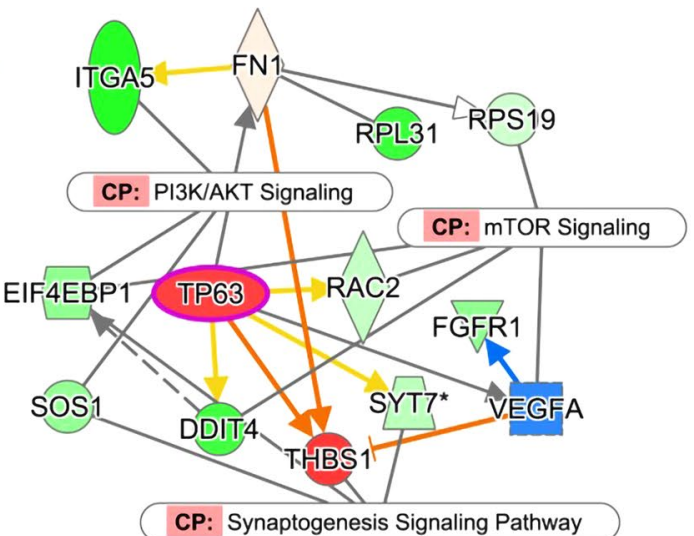

C

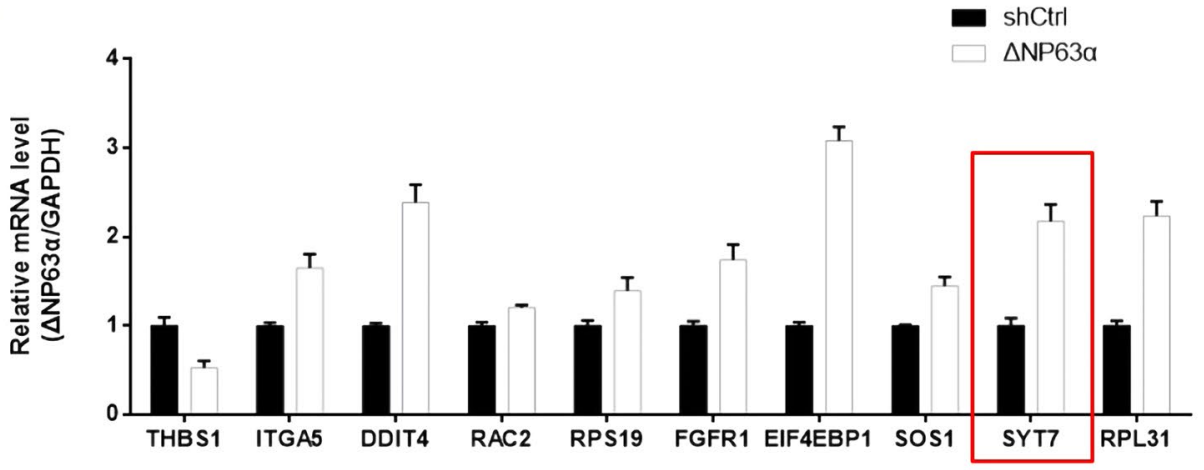

D

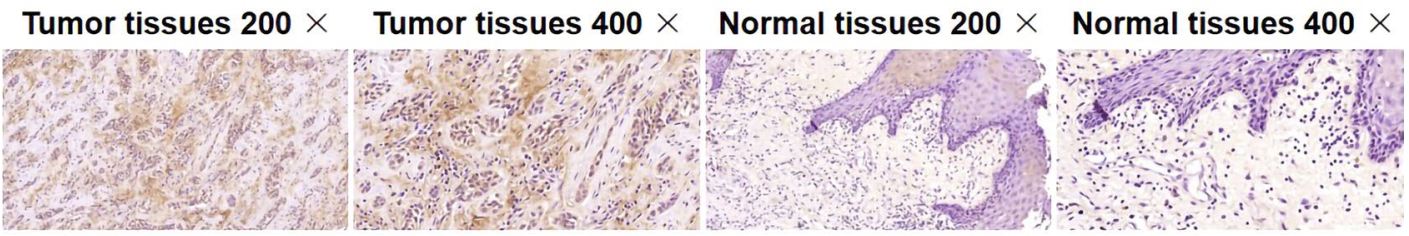

E

Top 30 of GO Enrichment

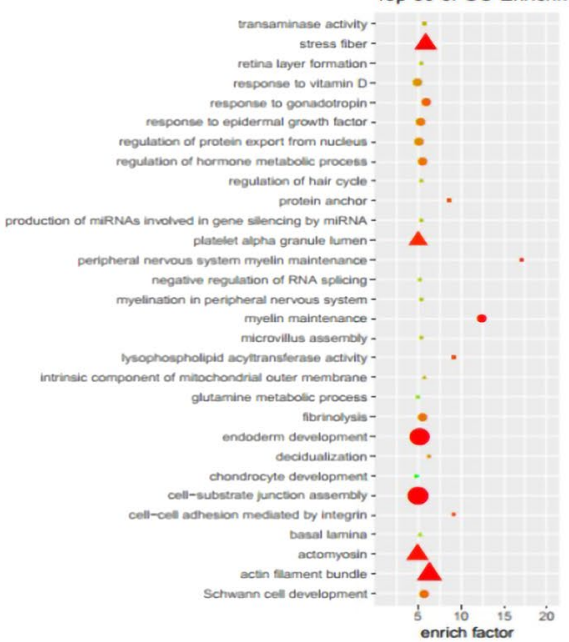

B

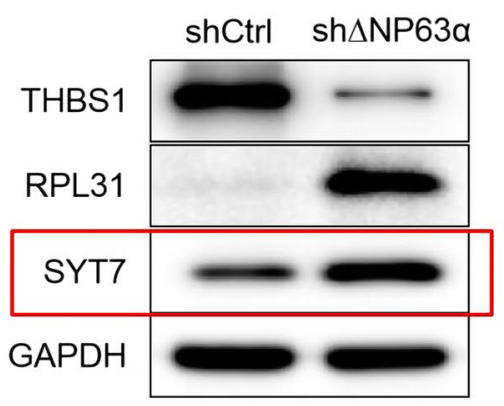

shCtrl

$\triangle N P 63 a$
F

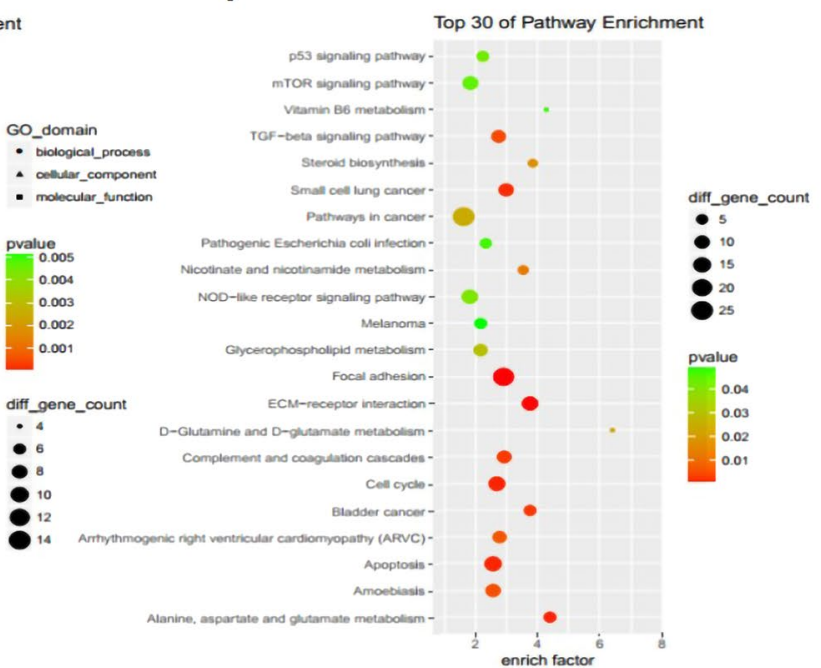

Fig. 3 Bioinformatic analysis of $\triangle N P 63 a-k n o c k d o w n$ cells. A IPA analysis of $\triangle N P 63 a-k n o c k d o w n$ cells. B Protein expression of between shCtrl cells and $\triangle N$ P63a-knockdown cells. $\mathbf{C}$ mRNA expression of between shCtrl cells and $\triangle N P 63 a-k n o c k d o w n$ cells. D Microarray detection of SYT7 expression in HNSCC samples and paired normal tissues. E GO enrichment of differential genes. F KEGG pathway enrichment of differential genes 
cells were detected at the protein and mRNA levels (Fig. 3B, C). Among them, SYT7 not only had a direct interaction with $\triangle \mathrm{Np} 63 \alpha$, but also was significantly enhanced at the mRNA and protein levels in $\Delta \mathrm{Np} 63 \alpha-$ knockdown cells, thereby it was selected as the downstream target gene of $\Delta \mathrm{Np} 63 \alpha$ to explore the role in HNSCC cell proliferation and migration.

Oral squamous cell carcinoma (OSCC) accounts for more than $90 \%$ of all histological subtypes of oral cancer, and is highly aggressive [23]. In this study, the results of immunohistochemical staining revealed that the levels of SYT7 in OSCC tissues was markedly higher that than in para-carcinoma tissues (Fig. 3D; Table 1). Further statistical analysis suggested that the expression of SYT7 gene was significantly different in the pathological grading of OSCC (Table 2), and there was a positive correlation (Table 3). Moreover, GO and KEGG enrichment was also conducted. Differentially expressed genes were mainly enriched in GO functions such as stress fiber, actomyosin, and actin filament bundle (Fig. 3E), and KEGG signaling pathways such as p53 signaling pathway, mTOR signaling pathway, Pathways in cancer, Cell cycle, and Apoptosis (Fig. 3F).

\section{Knockdown of SYT7 affected the proliferation and migration of HNSCC cells and the growth of tumor in vivo}

To identify the role of SYT7 in HNSCC, we established SYT7-knockdwon, in which SYT7 mRNA and protein levels were obviously diminished (Additional file 5: Fig. S3A-F). Besides, SYT7- $\triangle \mathrm{Np} 63 \alpha$ double knockdown cells was also constructed to study the effects of $\triangle \mathrm{Np} 63 \alpha$ and SYT7 interaction on HN6 and CAL-27 cells (Additional file 5: Fig. S3G-N). Celigo assays have been performed and results showed that knockdown of SYT7 markedly suppressed the proliferation of HNSCC cells in vitro (Fig. 4A, B, E, F), while SYT7- $\Delta$ Np63 $\alpha$ double knockdown could partially rescue this phenotype (Fig. 4C, D, G, H). Wound-healing assays showed that knockdown of SYT7 also inhibited the migration of HNSCC cells (Fig. 5A, C), and SYT7- $\Delta$ Np63 $\alpha$ double knockdown could partially alleviate the inhibition of

Table 1 Expression patterns in oral squamous cell carcinoma tissues and para-carcinoma tissues revealed in immunohistochemistry analysis

\begin{tabular}{|c|c|c|c|c|c|}
\hline \multirow[t]{2}{*}{$\begin{array}{l}\text { SYT7 } \\
\text { expression }\end{array}$} & \multicolumn{2}{|c|}{ Tumor tissue } & \multicolumn{2}{|c|}{$\begin{array}{l}\text { Para-carcinoma } \\
\text { tissue }\end{array}$} & \multirow[t]{2}{*}{$p$ value } \\
\hline & Cases & $\begin{array}{l}\text { Percentage } \\
\text { (\%) }\end{array}$ & Cases & $\begin{array}{l}\text { Percentage } \\
(\%)\end{array}$ & \\
\hline Low & 27 & 55.0 & 8 & 100.0 & $<0.001^{* * *}$ \\
\hline High & 33 & 45.0 & 0 & 0.0 & \\
\hline
\end{tabular}

Table 2 Relationship between SYT7 expression and tumor characteristics in patients with oral squamous cell carcinoma

\begin{tabular}{|c|c|c|c|c|}
\hline \multirow[t]{2}{*}{ Features } & \multirow{2}{*}{$\begin{array}{l}\text { No. of } \\
\text { patients }\end{array}$} & \multicolumn{2}{|c|}{ SYT7 expression } & \multirow[t]{2}{*}{$p$ value } \\
\hline & & Low & High & \\
\hline All patients & 60 & 27 & 33 & \\
\hline \multicolumn{2}{|l|}{ Age (years) } & & & 0.737 \\
\hline$\leq 64$ & 31 & 14 & 17 & \\
\hline$>64$ & 27 & 11 & 16 & \\
\hline \multicolumn{2}{|l|}{ Gender } & & & 0.486 \\
\hline Male & 28 & 11 & 17 & \\
\hline Female & 31 & 15 & 16 & \\
\hline \multicolumn{2}{|l|}{ Grade } & & & $<0.001^{* * *}$ \\
\hline 1 & 22 & 18 & 4 & \\
\hline 2 & 28 & 6 & 22 & \\
\hline 3 & 7 & 0 & 7 & \\
\hline \multicolumn{2}{|c|}{ Tumor size (cm) } & & & 0.757 \\
\hline$<2.5$ & 22 & 8 & 14 & \\
\hline$\geq 2.5$ & 27 & 11 & 16 & \\
\hline \multicolumn{2}{|c|}{ Lymph node positive } & & & 0.129 \\
\hline$=0$ & 25 & 13 & 12 & \\
\hline$>0$ & 9 & 2 & 7 & \\
\hline \multicolumn{3}{|c|}{ Lymphatic metastasis (N) } & & 0.129 \\
\hline No & 25 & 13 & 12 & \\
\hline N1 & 9 & 2 & 7 & \\
\hline
\end{tabular}

HNSCC cell migration by SYT7 downregulation (Fig. 5B, D). Then, flow cytometry was performed to the influence of SYT7-knockdwon and SYT7- $\Delta \mathrm{Np} 63 \alpha$ double knockdown on cell cycle and apoptosis. It was found that knockdown of SYT7 could clearly inducing apoptosis of HN6 and CAL-27 cells, while SYT7- $\Delta$ Np63 $\alpha$ double knockdown could partly restrict the induction of apoptosis of CAL-27 cell by shSYT7 lentivirus (Fig. 5E-H). Results showed that knockdown of SYT7 could also influence cell cycle of tumor cells (Fig. 5I-L). Furthermore, we also established a SYT7 knockdown HNSCC xenograft tumor model. In vivo imaging results indicated that the total fluorescence intensity in nude mice after SYT7 knockdown was lower than that of the control group (Fig. $6 \mathrm{~A}-\mathrm{C}$ ). In addition, the volume and weight of tumors in the SYT7 knockdown group were strikingly reduced than those in the control group, suggesting that

Table 3 Relationship between SYT7 expression and tumor characteristics in patients oral squamous cell carcinoma

\begin{tabular}{lll}
\hline & & SYT7 \\
\hline Grade & Spearman correlation & 0.643 \\
& Significance (two-tailed) & $<0.001^{* * *}$ \\
N & 57
\end{tabular}




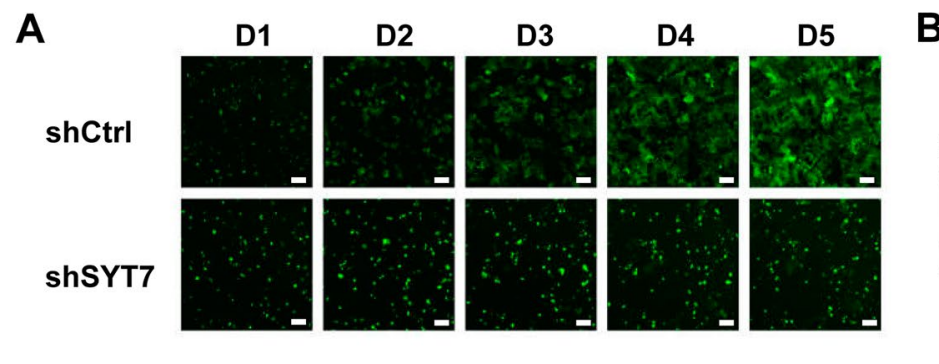

B
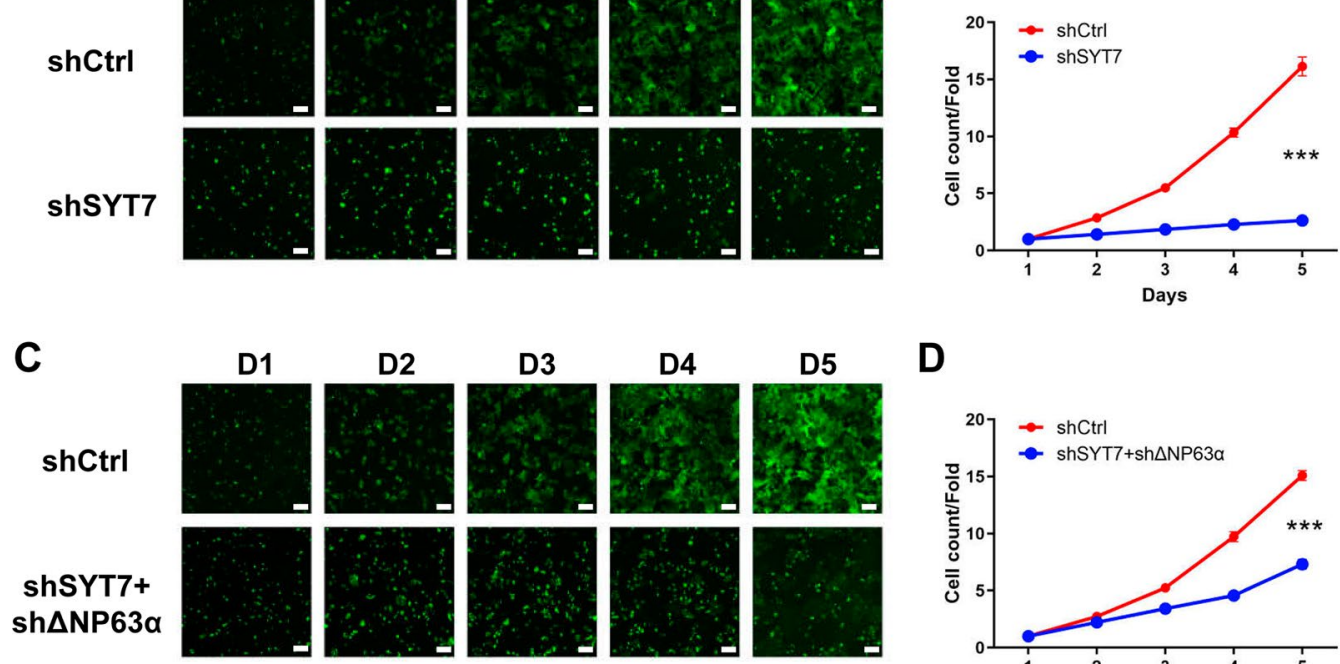

E

D1
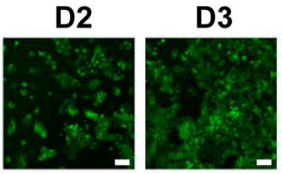

D4
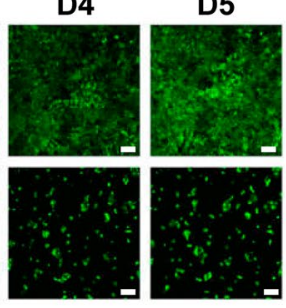

$\mathbf{F}$
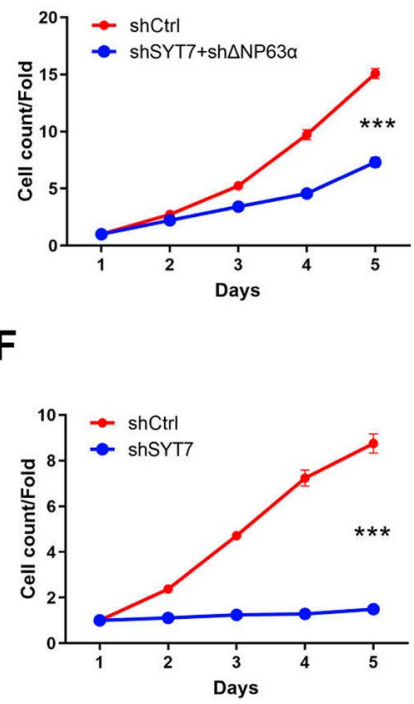

G

D1
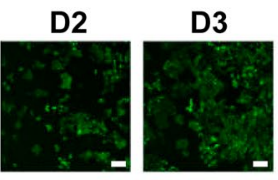

D4

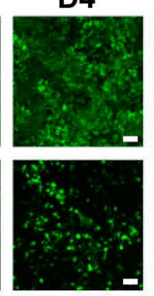

D5

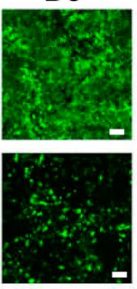

H

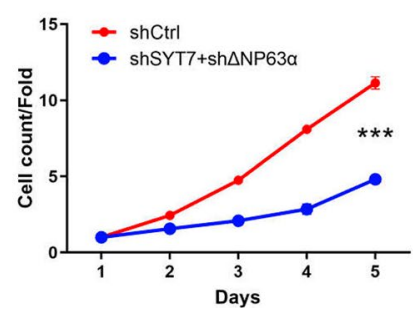

Fig. 4 Knockdown of SYT7 suppressed the proliferation of HN6 and CAL-27 cells and $\triangle N P 63 a-S Y T 7$ double knockdown could partially rescue this phenotype. A, B Detection of cell proliferation of SYT7-knockdown HN6 cells by Celigo cell count. C, D Detection of cell proliferation of $\triangle N P 63 a$ SYT7 double knockdown HN6 cells by Celigo cell count. E, F Detection of cell proliferation of SYT7-knockdown CAL-27 cells by Celigo cell count. G, $\mathbf{H}$ Detection of cell proliferation of $\triangle$ NP63a SYT7 double knockdown CAL-27 cells by Celigo cell count $(n=3)$. Bars show the mean \pm SD. ${ }^{* * *}$ Represents $p<0.001$. Scale bar $=100 \mu \mathrm{m}$

SYT7 knockdown significantly suppressed tumor growth in vivo (Fig. 6D-F).

\section{Discussion}

HNSCC is characterized as anatomical site complexity, intraneoplastic heterogeneity, genetic diversity among individuals $[24,25]$. Drug resistance, recurrence and metastasis is the most common death cause of HNSCC
[26, 27]. Due to the lack of more effective diagnostic and treatments, it is imperative to screen specific diagnostic and prognostic biomarkers. Our data indicated that $\Delta \mathrm{Np} 63 \alpha$ overexpression retarded the proliferation and migration of HNSCC cell lines (HN6 and CAL-27), and induced cell apoptosis. As a downstream target gene, SYT7 was highly expressed in HNSCC tissues and augmented by $\Delta \mathrm{Np} 63 \alpha$ knockdown. SYT7 silencing slowed 

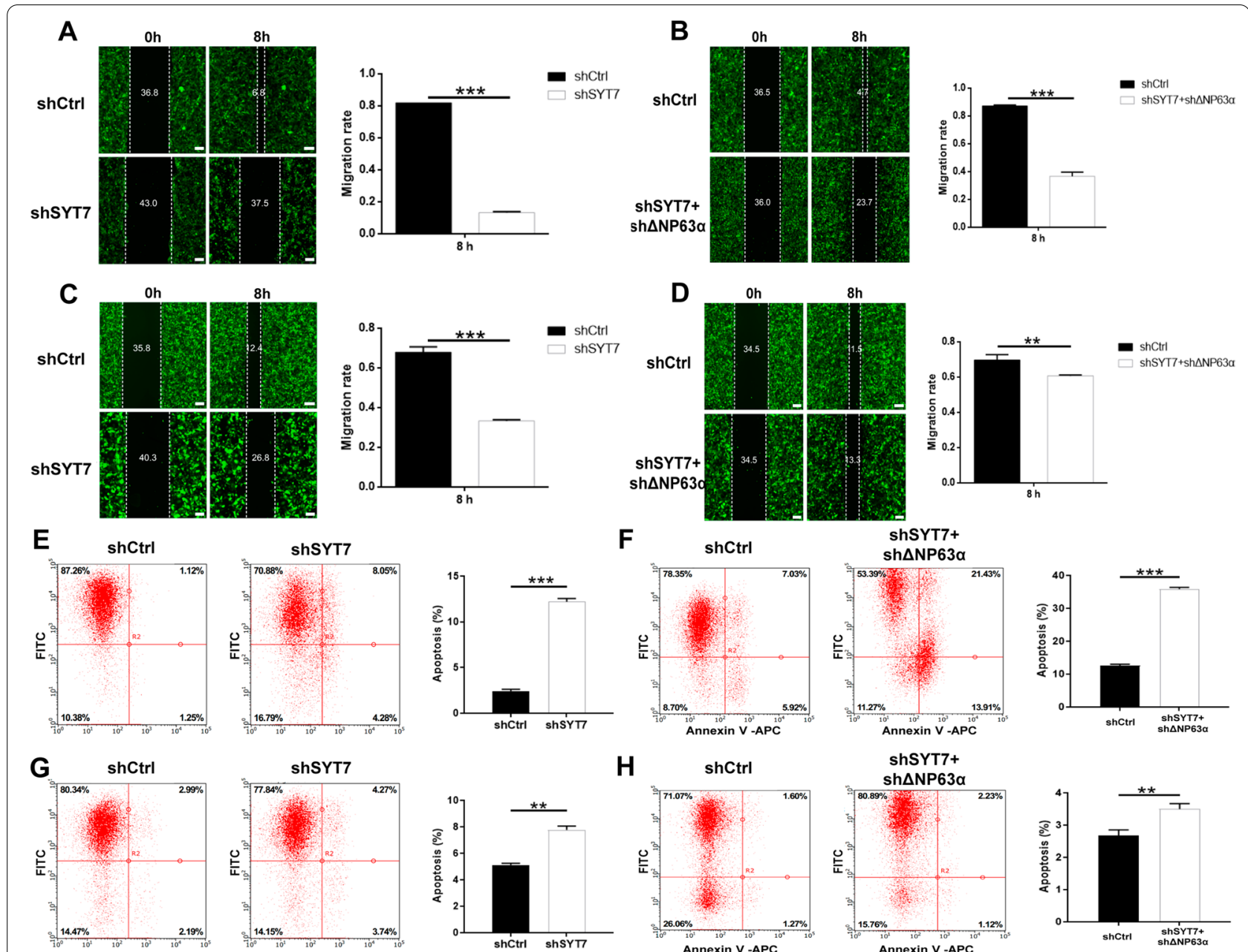

H
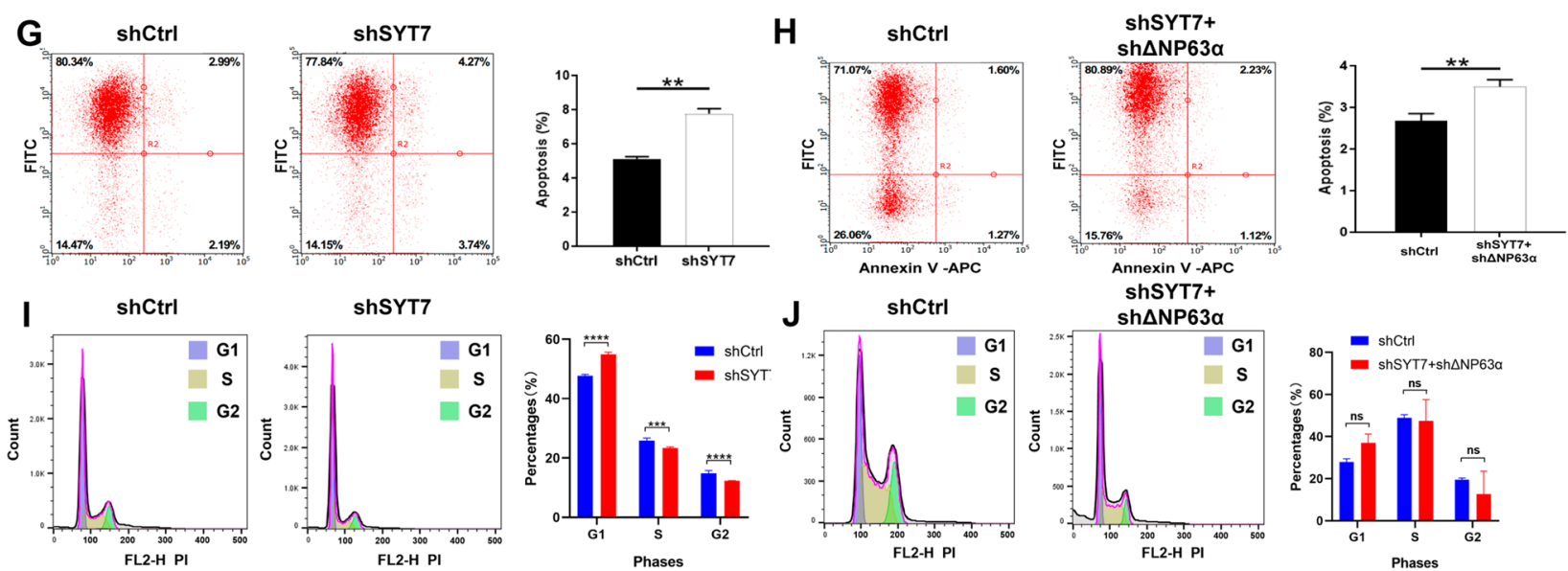

shSYT7+
Sh $\triangle$ NP63a
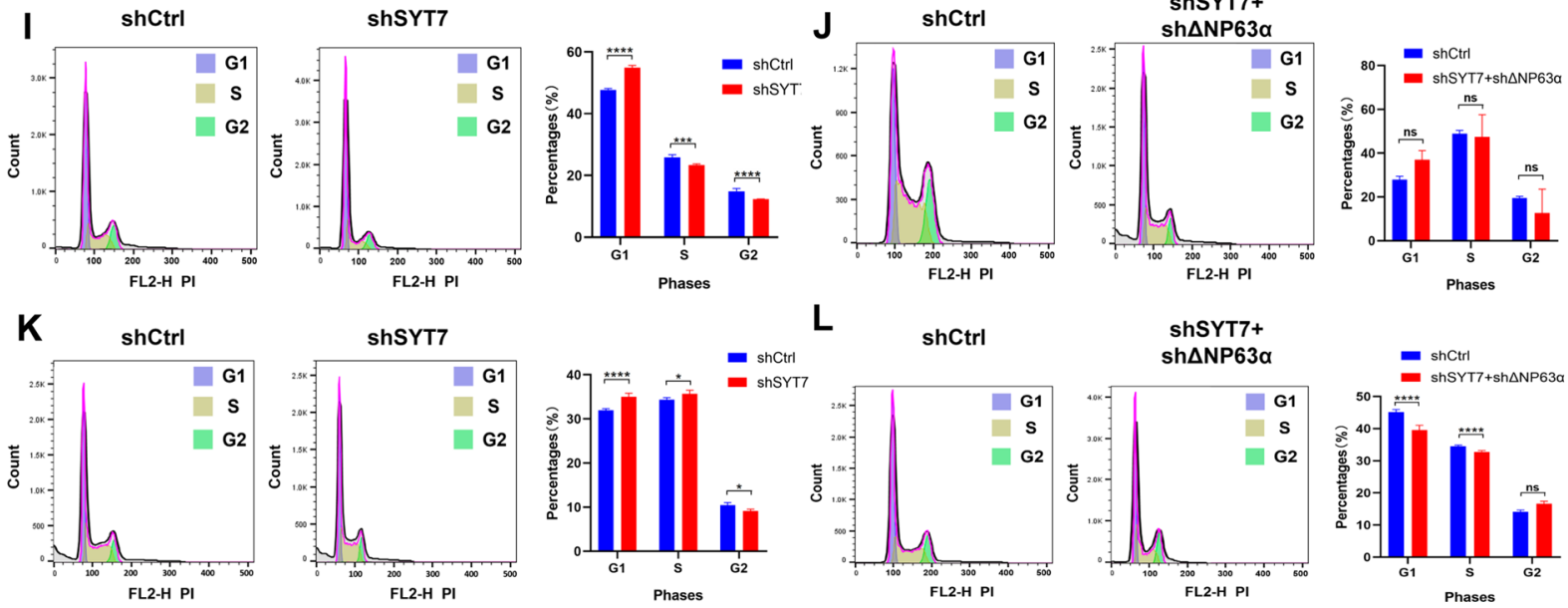

Fig. 5 Knockdown of SYT7 induced cell apoptosis and influenced cell cycle of HN6 and CAL-27 cells and $\triangle N P 63 a-S Y T 7$ double knockdown could partially rescue this phenotype. A Wound-healing analysis of SYT7-knockdown HN6 cells. B Wound-healing analysis of $\triangle N P 63$ a SYT7 double knockdown HN6 cells. C Wound-healing analysis of SYT7-knockdown CAL-27 cells. D Wound-healing analysis of $\triangle N P 63$ a SYT7 double knockdown CAL-27 cells. E Apoptosis assay of SYT7-knockdown and shCtrl HN6 cells. F Apoptosis assay of $\triangle N P 63$ a SYT7 double knockdown and shCtrl HN6 cells. G Apoptosis assay of SYT7-knockdown and shCtrl CAL-27 cells. H Apoptosis assay of $\triangle N P 63$ a SYT7 double knockdown and shCtrl CAL-27 cells. I Cell cycle detection of SYT7-knockdown and shCtrl HN6 cells. J Cell cycle detection of $\triangle N P 63$ a SYT7 double knockdown and shCtrl HN6 cells. K Cell cycle detection of SYT7-knockdown and shCtrl CAL-27 cells. L Cell cycle detection of $\triangle N P 63$ a SYT7 double knockdown and shCtrl CAL-27 cells $(n=3)$. Bars show the mean \pm SD. ${ }^{*}$ Represents $p<0.05$, ${ }^{* *}$ represents $p<0.01$, ${ }^{* * *}$ represents $p<0.001,{ }^{* * *}$ represents $p<0.0001$. Scale bar $=100 \mu \mathrm{m}$ 


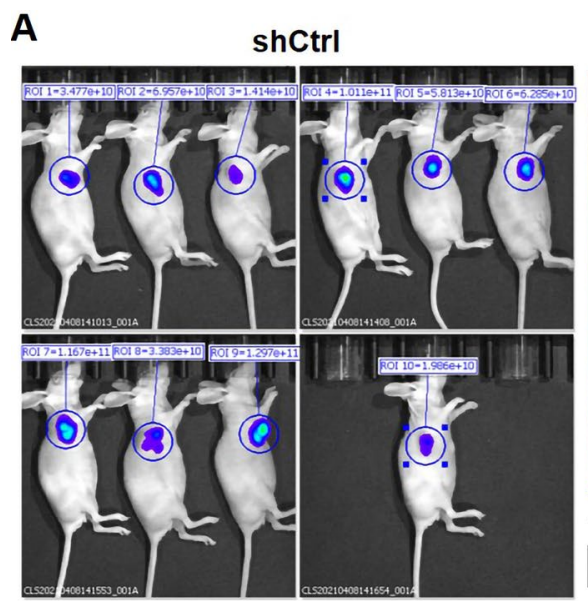

C

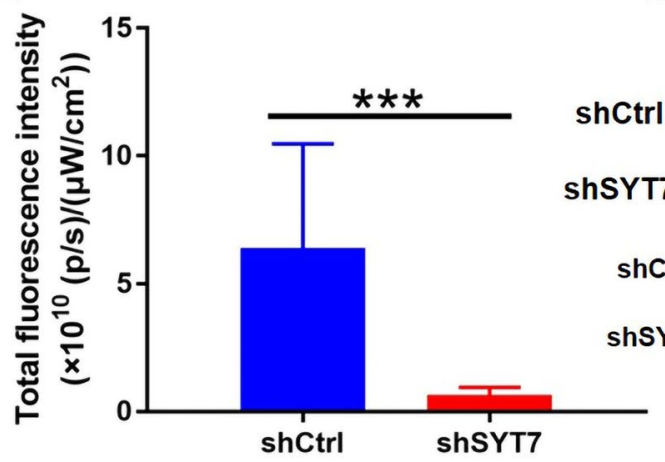

E

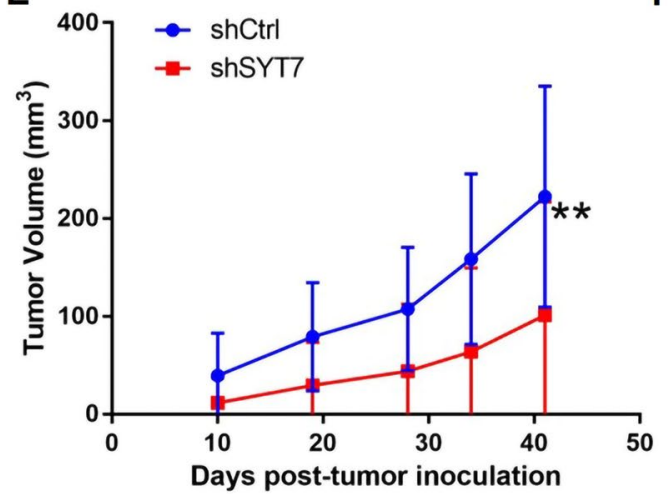

B

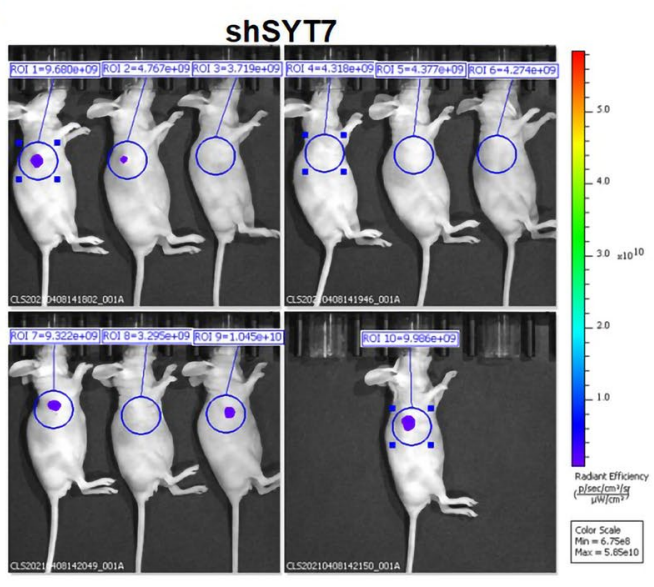

D

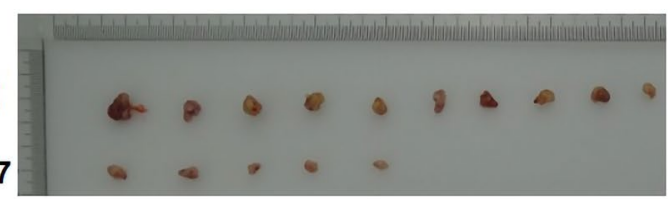

shCtrl \#8, \#3, \#9, \#7, \#4, \#10, \#1, \#2, \#5, \#6

shSYT7 \#11, \#20, \#17, \#12, \#19, \#13, \#14, \#15, \#16, \#18

$\mathbf{F}$

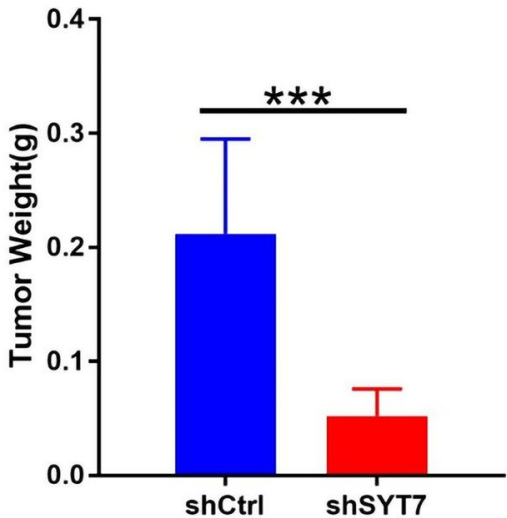

Fig. 6 Establishment of SYT7-knockdown xenograft tumor model in nude mice. A-C In vivo imaging analysis of nude mice after SYT7 knockdown. D Tumor samples from nude mice. E Tumor growth curve in nude mice with SYT7 knockdown. F Weight of tumors collected from nude mice $(n=10)$. Bars show the mean $\pm S D .{ }^{* *}$ Represents $p<0.01,{ }^{* * *}$ represents $p<0.001$

down the proliferation and migration of HNSCC cells, and increased the rate of apoptosis.

Previous studies have shown that $\Delta \mathrm{Np} 63 \alpha$ was overexpressed and associated with poor prognosis and survival, and partly triggered its tumorigenic effect by promoting proliferation and cell survival [28]. $\Delta \mathrm{Np} 63 \alpha$ activated the $\mathrm{Wnt} / \beta$-catenin signaling pathway through transcriptional regulation of RSK4, which played a key role in the progression and radioresistance of esophageal squamous cell carcinoma [29]. In addition, $\triangle \mathrm{Np} 63 \alpha$ inhibited the $\mathrm{PKC} \gamma / \mathrm{Rac} 1$ signaling pathway by positively regulating miR-320a, thereby inhibiting cancer invasion [30]. In our study, overexpression of $\Delta \mathrm{Np} 63 \alpha$ suppressed the proliferation and migration of HN6 and CAL-27 cells, induced apoptosis and affected the distribution of cell cycle, suggesting that $\Delta \mathrm{Np} 63 \alpha$ 
played a tumor suppressor effect in HNSCC. However, in the study of Jacky Chuang et al., $\Delta \mathrm{Np} 63 \alpha$ was a key pro-survival protein, which was overexpressed in $80 \%$ of HNSCC and enhanced the resistance of HNSCC to chemotherapy-induced cell death [31]. Therefore, the role of $\triangle \mathrm{Np} 63 \alpha$ in the progression of HNSCC needs further verification.

As the main isotype of the transcription factor TP63 expressed in squamous cell carcinoma, $\Delta \mathrm{Np} 63 \alpha$ played a tumor-promoting effect in squamous cell carcinoma by regulating the expression of different target genes [32]. In this study, it was confirmed that there was an interaction relationship between SYT7 and $\Delta \mathrm{Np} 63 \alpha$ through Affymetrix expression profile assay and IPA and other bioinformatic analysis, and $\Delta \mathrm{Np} 63 \alpha$ knockdown boosted the levels of SYT7 mRNA and protein. SYT7 was a $\mathrm{Ca}^{2+}$ sensor which had a variety of functions and expressed throughout the whole body. SYT7 had great affinity to $\mathrm{Ca}^{2+}$ and played a significant role in the process of modest calcium increased [33]. In non-small cell lung cancer, the expression of SYT7 was distinctly higher than that of para-carcinoma tissues, and the high expression of SYT7 protein was related to the low survival rate of patients [20]. Moreover, compared with normal tissues, the levels of SYT7 in colorectal cancer tissues were up-regulated and were positively correlated with pathological staging. Knockdown of SYT7 gene inhibited cell proliferation and clonal formation, and promoted G2/M phase arrest and apoptosis [21]. In the study, the expression level of SYT7 in OSCC tumor tissues was higher than that in para-carcinoma tissues. The expression of SYT7 gene was significantly different in the pathological grading of OSCC, and there was a positive correlation.

Mitsuro Kanda et al. determined that SYT7 was highly expressed in gastric cancer tissues with liver metastases. SYT7 gene knockdown inhibited GC progression and metastasis, which was manifested by increased apoptosis and weakened cell migration, invasion and adhesion [22]. In our study, we established SYT7 knockdown cells in two HNSCC cell lines, HN6 and CAL-27. Results showed that knockdown of SYT7 remarkably inhibited proliferation and migration, and induced apoptosis and cell cycle. Nevertheless, this phenotype could be rescued by $\Delta \mathrm{Np} 63 \alpha$ and SYT7 double knockdown. These results demonstrated that SYT7 was an oncogene in HNSCC and regulated by $\Delta \mathrm{Np} 63 \alpha$. However, there are still some shortcoming in this study. We should detect the expression levels of $\triangle \mathrm{Np} 63 \alpha$ in HNSCC tissues and para-carcinoma tissues. Besides, we did not further evaluate the correlation between the expression of SYT7 in HNSCC and tumor pathological characteristics by statistical analysis.

\section{Conclusions}

In summary, our study demonstrated that $\Delta \mathrm{Np} 63 \alpha$ played a role in HNSCC as a tumor suppressor gene, and SYT7 played a significant role in cell proliferation, migration, apoptosis and cell cycle of HNSCC tumor cells under the regulation of $\Delta \mathrm{Np} 63 \alpha$. We first reported SYT7 as an oncogene and a potential diagnostic and prognostic biomarker in HNSCC, thus, SYT7 was considered to be a promising diagnostic and therapeutic target for HNSCC patients.

\section{Supplementary Information}

The online version contains supplementary material available at https://doi. org/10.1186/s12935-021-02394-w.

\begin{abstract}
Additional file 1: Table S1. Primers used in qPCR.
Additional file 2: Table S2. Antibodies used in westernblotting and $\mathrm{IHC}$

Additional file 3: Figure S1. Establishment of $\triangle N P 63 a$-overexpressed cells. A-D The fluorescence observation of $\triangle N P 63 a-o v e r e x p r e s s e d$ HN6 cells. $\mathbf{E}-\mathbf{H}$ The fluorescence observation of $\triangle N P 63 a$-overexpressed CAL-27 cells. I The expression levels of $\triangle N P 63 a$ mRNA in $\triangle N P 63 a-$ overexpressed HN6 cells. JThe expression levels of $\triangle N P 63$ a mRNA in $\triangle N P 63 a-o v e r e x p r e s s e d ~ C A L-27$ cells. $\mathbf{K}$ The expression levels of $\triangle N P 63 a$ protein in $\triangle N P 63 a-o v e r e x p r e s s e d ~ H N 6$ cells. L The expression levels of $\triangle N P 63 a$ protein in $\triangle N P 63 a-o v e r e x p r e s s e d ~ C A L-27$ cells $(n=3)$. Bars show the mean $\pm S D$. *Represents $p<0.05$, **represents $p<0.01$. Scale
\end{abstract} bar $=100 \mu \mathrm{m}$.

Additional file 4: Figure S2. Cell proliferation analysis of $\triangle N P 63 a-$ overexpressed cells. A MTT assay of HN6 cells. B MTT assay of CAL-27 cells $(n=3)$. Bars show the mean \pm SD. ${ }^{* * *}$ Represents $p<0.001$.

Additional file 5: Figure S3. Establishment of SYT7-knockdown cells and $\triangle$ NP63a SYT7 double knockdown cells. A The fluorescence observation of SYT7-knockdown HN6 cells. B The fluorescence observation of SYT7-knockdown CAL-27 cells. C The expression levels of SYT7 mRNA in SYT7-knockdown HN6 cells. D The expression levels of SYT7 protein in SYT7-knockdown HN6 cells. E The expression levels of SYT7 mRNA in SYT7-knockdown CAL-27 cells. F The expression levels of SYT7 protein in SYT7-knockdown CAL-27 cells. G The fluorescence observation of $\triangle N P 63 a$ SYT7 double knockdown HN6 cells. $\mathbf{H}$ The fluorescence observation of $\triangle N P 63 a$ SYT7 double knockdown CAL-27 cells. I-J The expression levels of $\triangle N P 63 a$ and SYT7 mRNA in $\triangle N P 63 a$ SYT7 double knockdown HN6 cells. $\mathbf{K}-\mathbf{L}$ The expression levels of $\triangle N P 63 a$ and SYT7 mRNA in $\triangle N P 63 a$ SYT7 double knockdown CAL-27 cells. $\mathbf{M}$ The expression levels of $\triangle N P 63 a$ and SYT7 protein in $\triangle N P 63$ a SYT7 double knockdown HN6 cells. NThe expression levels of $\triangle N P 63 a$ and SYT7 protein in $\triangle N P 63 a$ SYT7 double knockdown CAL-27 cells $(n=3)$. Bars show the mean $\pm S D$. *Represents $p<0.05$, **represents $p<0.01,{ }^{* * *}$ represents $p<0.001$. Scale bar $=100 \mu \mathrm{m}$.

\section{Acknowledgements}

We thank The Ninth People's Hospital affiliated to the Shanghai Jiao Tong University School of Medicine supported by the National Natural Science Foundation of China (Grant No. 81802697) and CAMS Innovation Fund for Medical Sciences (CIFMS) Project No. 2019-I2M-5-037) for approving.

\section{Authors' contributions}

YF and GT made substantial contributions to the conception and design of the study and acquisition, analysis, and interpretation of data for the study. ZZ made substantial contributions to the conception and design of the study and together with the other authors, gave the final approval of the version to be published and agreement to be accountable for all aspects of the work in ensuring that questions related to the accuracy or integrity of any part of the work are appropriately investigated and resolved. XY was involved in the drafting of the study or revising it critically for important intellectual content, 
as well as in the acquisition, analysis, or interpretation of data for the study. All authors read and approved the final manuscript.

\section{Funding}

The present study was supported by The Ninth People's Hospital affiliated to the Shanghai Jiao Tong University School of Medicine supported by the National Natural Science Foundation of China (Grant No. 81802697) and CAMS Innovation Fund for Medical Sciences (CIFMS) (Project No. 2019-I2M-5-037).

\section{Availability of data and materials}

All data generated or analyzed during this study are included in this published article or are available from the corresponding author on reasonable request.

\section{Declarations}

\section{Ethics approval and consent to participate}

All producers were approved by Shanghai Jiao Tong University Animal Ethics Committee. All animal experiments operated in this research were completed in keeping with the guidelines of the Shanghai Jiao Tong University School of Medicine.

\section{Consent for publication}

Not applicable.

\section{Competing interests}

The authors declare that they have no competing interests.

\section{Author details}

'Department of Oral and Maxillofacial-Head Neck Oncology, Shanghai Ninth People's Hospital, Shanghai Jiao Tong University School of Medicine, College of Stomatology, National Center for Stomatology, National Clinical Research Center for Oral Diseases, Shanghai Jiao Tong University, 639 Zhizaoju Road, Shanghai 200011, People's Republic of China. ${ }^{2}$ Department of Oral and Cranio-maxillofacial Surgery, Shanghai Ninth People's Hospital, Shanghai Jiao Tong University School of Medicine, College of Stomatology, National Center for Stomatology, National Clinical Research Center for Oral Diseases, Shanghai Jiao Tong University, 639 Zhizaoju Road, Shanghai 200011, People's Republic of China. ${ }^{3}$ Shanghai Key Laboratory of Stomatology, Research Unit of Oral and Maxillofacial Regenerative Medicine, Chinese Academy of Medical Sciences, Beijing, China.

Received: 22 Auqust 2021 Accepted: 5 December 2021 Published online: 20 December 2021

\section{References}

1. Siegel RL, Miller KD, Jemal A. Cancer statistics, 2016. CA Cancer J Clin. 2016;66(1):7-30.

2. Torre LA, Bray F, Siegel RL, Ferlay J, Lortet-Tieulent J, Jemal A. Global cancer statistics, 2012. CA Cancer J Clin. 2015;65(2):87-108.

3. Gillison ML, Chaturvedi AK, Anderson WF, Fakhry C. Epidemiology of human papillomavirus-positive head and neck squamous cell carcinoma. J Clin Oncol. 2015;33(29):3235-42.

4. Miyauchi S, Kim SS, Pang J, Gold KA, Gutkind JS, Califano JA, et al. Immune modulation of head and neck squamous cell carcinoma and the tumor microenvironment by conventional therapeutics. Clin Cancer Res. 2019;25(14):4211-23

5. Wu XL, Tu Q, Faure G, Gallet P, Kohler C, Bittencourt Mde C. Diagnostic and prognostic value of circulating tumor cells in head and neck squamous cell carcinoma: a systematic review and meta-analysis. Sci Rep. 2016;6:20210.

6. Sacco AG, Cohen EE. Current treatment options for recurrent or metastatic head and neck squamous cell carcinoma. J Clin Oncol. 2015;33(29):3305-13

7. Pollock NI, Grandis JR. HER2 as a therapeutic target in head and neck squamous cell carcinoma. Clin Cancer Res. 2015;21(3):526-33.

8. Citro S, Bellini A, Medda A, Sabatini ME, Tagliabue M, Chu F, et al. Human papilloma virus increases DeltaNp63alpha expression in head and neck squamous cell carcinoma. Front Cell Infect Microbiol. 2020;10:143.
9. Yang A, Kaghad M, Caput D, McKeon F. On the shoulders of giants: p63, p73 and the rise of p53. Trends Genet. 2002;18(2):90-5.

10. Kajiwara C, Fumoto K, Kimura H, Nojima S, Asano K, Odagiri K, et al. p63-Dependent Dickkopf3 expression promotes esophageal cancer cell proliferation via CKAP4. Cancer Res. 2018;78(21):6107-20.

11. Yi Y, Chen D, Ao J, Zhang W, Yi J, Ren X, et al. Transcriptional suppression of AMPKalpha1 promotes breast cancer metastasis upon oncogene activation. Proc Natl Acad Sci USA. 2020;117(14):8013-21.

12. Moses MA, George AL, Sakakibara N, Mahmood K, Ponnamperuma RM, King KE, et al. Molecular mechanisms of p63-mediated squamous cancer pathogenesis. Int J Mol Sci. 2019;20(14):3590.

13. Chen J, Liu A, Wang Z, Wang B, Chai X, Lu W, et al. LINC00173.v1 promotes angiogenesis and progression of lung squamous cell carcinoma by sponging miR-511-5p to regulate VEGFA expression. Mol Cancer. 2020;19(1):98.

14. Zhao G, Li R, Cao Y, Song M, Jiang P, Wu Q, et al. DeltaNp63alpha-induced DUSP4/GSK3beta/SNAI1 pathway in epithelial cells drives endometrial fibrosis. Cell Death Dis. 2020;11(6):449.

15. Zhou Y, Liu H, Wang J, Wang X, Qian L, Xu F, et al. DeltaNp63alpha exerts antitumor functions in cervical squamous cell carcinoma. Oncogene. 2020;39(4):905-21.

16. Turecek J, Jackman SL, Regehr WG. Synaptotagmin 7 confers frequency invariance onto specialized depressing synapses. Nature. 2017:551(7681):503-6.

17. Jackman SL, Turecek J, Belinsky JE, Regehr WG. The calcium sensor synaptotagmin 7 is required for synaptic facilitation. Nature. 2016;529(7584):88-91.

18. Chu M, Wan H, Zhang X. Requirement of splicing factor hnRNP A2B1 for tumorigenesis of melanoma stem cells. Stem Cell Res Ther. 2021;12(1):90

19. Li L, Zhao S, Liu Z, Zhang N, Pang S, Liu J, et al. Sunitinib treatment promotes metastasis of drug-resistant renal cell carcinoma via TFE3 signaling pathway. Cell Death Dis. 2021;12(2):220.

20. Liu X, Li C, Yang Y, Liu X, Li R, Zhang M, et al. Synaptotagmin 7 in twistrelated protein 1-mediated epithelial-mesenchymal transition of nonsmall cell lung cancer. EBioMedicine. 2019;46:42-53.

21. Wang $\mathrm{K}$, Xiao H, Zhang J, Zhu D. Synaptotagmin7 is overexpressed in colorectal cancer and regulates colorectal cancer cell proliferation. J Cancer. 2018:9(13):2349-56.

22. Kanda M, Tanaka H, Shimizu D, Miwa T, Umeda S, Tanaka C, et al. SYT7 acts as a driver of hepatic metastasis formation of gastric cancer cells. Oncogene. 2018;37(39):5355-66.

23. Pai S, Bamodu OA, Lin YK, Lin CS, Chu PY, Chien MH, et al. CD47-SIRPalpha signaling induces epithelial-mesenchymal transition and cancer stemness and links to a poor prognosis in patients with oral squamous cell carcinoma. Cells. 2019;8(12):1658.

24. Jung K, Narwal M, Min SY, Keam B, Kang H. Squamous cell carcinoma of head and neck: what internists should know. Korean J Intern Med. 2020;35(5):1031-44

25. Canning M, Guo G, Yu M, Myint C, Groves MW, Byrd JK, et al. Heterogeneity of the head and neck squamous cell carcinoma immune landscape and its impact on immunotherapy. Front Cell Dev Biol. 2019;7:52.

26. Hutchinson MND, Mierzwa M, D'Silva NJ. Radiation resistance in head and neck squamous cell carcinoma: dire need for an appropriate sensitizer. Oncogene. 2020;39(18):3638-49.

27. Bossi P, Alfieri S, Strojan P, Takes RP, Lopez F, Makitie A, et al. Prognostic and predictive factors in recurrent and/or metastatic head and neck squamous cell carcinoma: a review of the literature. Crit Rev Oncol Hematol. 2019:137:84-91.

28. Stacy AJ, Zhang J, Craig MP, Hira A, Dole N, Kadakia MP. TIP60 upregulates DeltaNp63alpha to promote cellular proliferation. J Biol Chem. 2019;294(45):17007-16

29. Li MY, Fan LN, Han DH, Yu Z, Ma J, Liu YX, et al. Ribosomal S6 protein kinase 4 promotes radioresistance in esophageal squamous cell carcinoma. J Clin Invest. 2020;130(8):4301-19.

30. Aljagthmi AA, Hill NT, Cooke M, Kazanietz MG, Abba MC, Long W, et al. DeltaNp63alpha suppresses cells invasion by downregulating PKCgamma/Rac1 signaling through miR-320a. Cell Death Dis. 2019;10(9):680

31. Chung J, Lau J, Cheng LS, Grant RI, Robinson F, Ketela T, et al. SATB2 augments DeltaNp63alpha in head and neck squamous cell carcinoma. EMBO Rep. 2010;11(10):777-83. 
32. Yi M, Tan Y, Wang L, Cai J, Li X, Zeng Z, et al. TP63 links chromatin remodeling and enhancer reprogramming to epidermal differentiation and squamous cell carcinoma development. Cell Mol Life Sci. 2020;77(21):4325-46.

33. Sleiman M, Stevens DR, Chitirala P, Rettig J. Cytotoxic granule trafficking and fusion in synaptotagmin7-deficient cytotoxic T lymphocytes. Front Immunol. 2020;11:1080.

\section{Publisher's Note}

Springer Nature remains neutral with regard to jurisdictional claims in published maps and institutional affiliations.

- fast, convenient online submission

- thorough peer review by experienced researchers in your field

- rapid publication on acceptance

- support for research data, including large and complex data types

- gold Open Access which fosters wider collaboration and increased citations

- maximum visibility for your research: over $100 \mathrm{M}$ website views per year

At $\mathrm{BMC}$, research is always in progress.

Learn more biomedcentral.com/submissions 